\title{
Neural Network based control of Doubly-Fed Induction Generator in wind power generation
}

\author{
Swati A. Barbade ${ }^{1}$, Prabha. Kasliwal ${ }^{2}$ \\ P.G student, Dept of Electronics, Maharashtra Academy of Engineering, India \\ Asst. Prof., Dept of Electronics, Maharashtra Academy of Engineering, India.
}

\begin{abstract}
To complement the other types of pollution-free generation wind energy is a viable option. Previously wind turbines were operated at constant speed. The evolution of technology related to wind systems industry leaded to the development of a generation of variable speed wind turbines that present many advantages compared to the fixed speed wind turbines. In this paper the phasor model of DFIG is used. This paper presents a study of a doubly fed induction generator driven by a wind turbine connected to the grid, and controlled by artificial neural network ANN controller. The behaviour of the system is shown with PI control, and then as controlled by ANN. The effectiveness of the artificial neural network controller is compared to that of a PI controller. The SIMULINK/MATLAB simulation for Doubly Fed Induction Generator and corresponding results and waveforms are displayed.
\end{abstract}

Keywords: Control, Doubly fed induction generator Neural networks, Variable speed, Wind power Generation,

\section{Introduction}

Over the past few years, wind energy has shown the fastest rate of growth of any form of electricity generation with its development stimulated by concerns of national policy makers over climate change, energy diversity and security of supply. Wind technology has to cope with the intermittent and seasonal variability of the wind. During normal condition the control begins to work when wind speed is above the cut-in speed so that power is injected into the utility grid; moreover they include some mechanisms to limit the captured power at high wind speeds to prevent overloading. New wind turbine technology integrates power electronics and control making it possible for wind power generation to participate in active and reactive power control. wind energy conversion systems (WECSs) connected to the grid must be designed to minimize the cost of supplied energy ensuring safe operation, acoustic emission and grid connection requirements. Control objectives involved in wind energy conversion systems are:

- energy capture;

- mechanical load;

- grid connection requirements.

Control strategies were developed for purpose of extracting the maximum wind power. A way to make more controllable turbines is variable speed turbines.

Variable speed turbines have become the most dominating type of the early installed wind turbines [1-2]; as they can store some of the power fluctuations due to turbulence by increasing the rotor speed, pitching the rotor blades, these

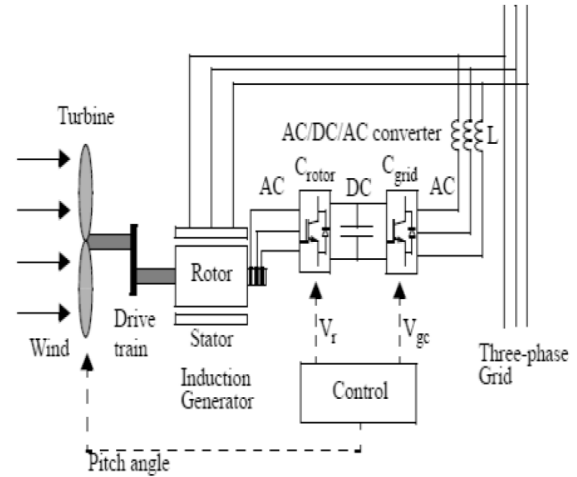

Fig.1 basic diagram of doubly fed induction generator with converters

turbines can control the power output at any given wind speed [3]. There are two main control technique: the vector control (VC) and the direct torque control (DTC) used for high performance applications. Based on the induction machines, the vector control (VC) of $\mathrm{AC}$ machines have become the most adopted control technique worldwide [4-5]. 
Artificial intelligence techniques are used for the purpose of controlling the system. It requires intelligent system such as fuzzy logic, neural networks, genetic algorithms and particle swarm optimization. The decisions are taken on the basis of the database provided to control the system instead of the mathematical analysis. These intelligent techniques have been used to control the wind energy such as optimal design using particle swarm optimization of proportional-integral controllers for the Doubly-Fed Induction Generator (DFIG) is presented in [6], Fuzzy logic control of a variable-speed wind generation system that uses a cage-type induction generator and a back-to-back full power converter [7].

The basic diagram of DFIG is shown in Fig 1. Wind turbines use a doubly-fed induction generator (DFIG) consisting of a wound rotor induction generator and an AC/DC/AC IGBT-based PWM converter. The stator winding is connected directly to the grid while the rotor is fed at variable frequency through the AC/DC/AC converter. The DFIG technology allows extracting maximum energy from the wind for low wind speeds by optimizing the turbine speed, while minimizing mechanical stresses on the turbine during gusts of wind. Another advantage of the DFIG technology is the ability for power electronic converters to generate or absorb reactive power, thus eliminating the need for installing capacitor banks as in the case of squirrel-cage induction generator. Where $\mathrm{V}_{\mathrm{r}}$ is the rotor voltage and $\mathrm{Vgc}$ is grid side voltage. The AC/DC/AC converter is basically a PWM converter which uses sinusoidal PWM technique to reduce the harmonics present in the wind turbine driven DFIG system. Here $\mathrm{C}_{\text {rotor }}$ is rotor side converter and $\mathrm{C}_{\text {grid }}$ is grid side converter. To control the speed of wind turbine gear boxes or electronic control can be used. According to certain conditions of the system parameters such as rotor speed, methods should be used to control the system in order to impose optimal power in the machine.

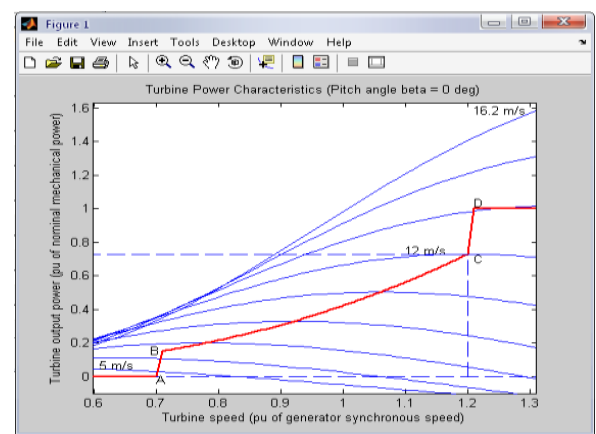

Fig.2 turbine power characteristics

\section{METHODOLOGY}

The back to back PWM converter has two converters, one is connected to rotor side and another is connected to grid side. The rotor-side converter is used to control the wind turbine output power and the voltage measured at the grid terminals. The power is controlled in order to follow a pre-defined power-speed characteristic, named tracking characteristic as shown in Fig.2. This characteristic is illustrated by the ABCD curve superimposed to the mechanical power characteristics of the turbine obtained at different wind speeds. The actual speed of the turbine $\omega_{\mathrm{r}}$ is measured and the corresponding mechanical power of the tracking characteristic is used as the reference power for the power control loop. The tracking characteristic is defined by four points: A, B, C and D. From zero speed to speed of point A the reference power is zero. Between point A and point $B$ the tracking characteristic is a straight line. Between point $B$ and point $C$ the tracking characteristic is the locus of the maximum power of the turbine (maxima of the turbine power versus turbine speed curves). The tracking characteristic is a straight line from point $\mathrm{C}$ and point $\mathrm{D}$. The power at point $\mathrm{D}$ is one per unit. Beyond point $\mathrm{D}$ the reference power is a constant equal to one per unit.

\subsection{Rotor side controller block diagram}

For the rotor-side controller the d-axis of the rotating reference frame used for d-q transformation is aligned with air-gap flux. The actual electrical output power, measured at the grid terminals of the wind turbine, is added to the total power losses (mechanical and electrical) and is compared with the reference power obtained from the tracking characteristic. A Proportional-Integral (PI) regulator is used to reduce the power error to zero. The output of this regulator is the reference rotor current $\mathrm{I}_{\mathrm{qr} \_ \text {ref }}$ that must be injected in the rotor by converter $\mathrm{C}_{\text {rotor. }}$. This is the current component that produces the electromagnetic torque Tem. The actual $\mathrm{I}_{\mathrm{qr}}$ component is compared to $\mathrm{I}_{\mathrm{qr} \_ \text {ref }}$ and the error is reduced to zero by a current regulator (PI). The output of this current controller is the voltage $\mathrm{V}_{\mathrm{qr}}$ generated by $\mathrm{C}_{\text {rotor }}$. The current regulator is assisted by feed forward terms which predict $\mathrm{V}_{\mathrm{qr}}$. The voltage at grid terminals is controlled by the reactive power generated or absorbed by the converter $\mathrm{C}_{\text {rotor }}$. The reactive power is exchanged between $\mathrm{C}_{\text {rotor }}$ and the grid, through the generator. In the exchange process the generator absorbs reactive power to supply its mutual and leakage inductances. The excess of reactive power is sent to the grid or to $\mathrm{C}_{\text {rotor }}$. 
When the wind turbine is operated in var regulation mode the reactive power at grid terminals is kept constant by a var regulator. The output of the voltage regulator or the var regulator is the reference d-axis current $\mathrm{I}_{\mathrm{dr} \_ \text {ref }}$ that must be injected in the rotor by converter $\mathrm{C}_{\text {rotor. }}$. The same current regulator as for the power control is used to regulate the actual $\mathrm{I}_{\mathrm{dr}}$ component of positive-sequence current to its reference value. The output of this regulator is the $\mathrm{d}$-axis voltage $\mathrm{V}_{\mathrm{dr}}$ generated by $\mathrm{C}_{\text {rotor. }}$. The current regulator is assisted by feed forward terms which predict $\mathrm{V}_{\mathrm{dr}} . \mathrm{V}_{\mathrm{dr}}$ and $\mathrm{V}_{\mathrm{qr}}$ are respectively the d-axis and q-axis of the voltage $\mathrm{V}_{\mathrm{r}}$.

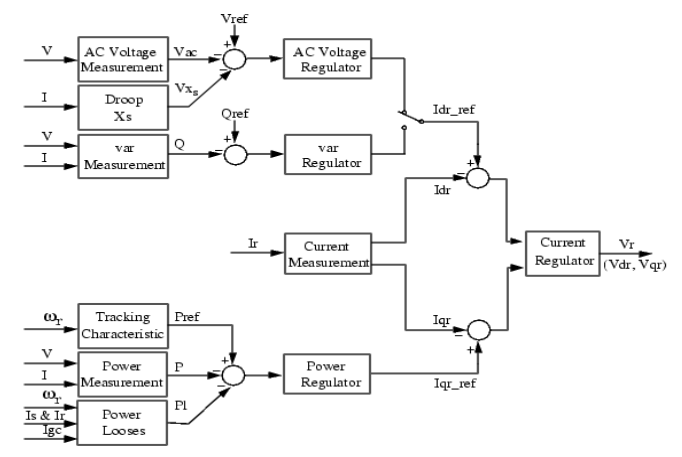

Fig. 3 rotor converter control block diagram.

\section{2 .Grid side converter control system}

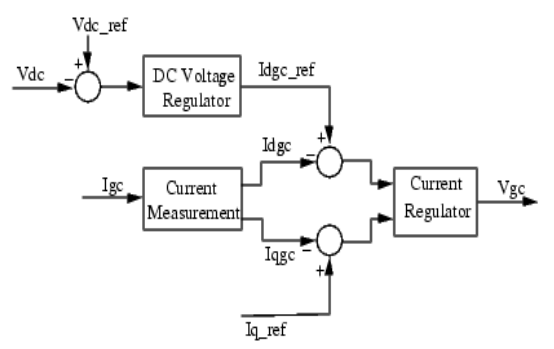

Fig.4 grid side converter control diagram.

The Grid side converter is used to regulate the voltage of the DC bus capacitor. For the grid-side controller the $d$-axis of the rotating reference frame used for $d$-q transformation is aligned with the positive sequence of grid voltage. This controller consists of:

1. A measurement system measuring the $\mathrm{d}$ and q components of $\mathrm{AC}$ currents to be controlled as well as the

DC voltage $\mathrm{V}_{\mathrm{dc}}$.

2. An outer regulation loop consisting of a DC voltage Regulator.

3. An inner current regulation loop consisting of a current Regulator

The current regulator controls the magnitude and phase of the voltage generated by converter $\mathrm{C}_{\text {grid }}\left(\mathrm{V}_{\mathrm{gc}}\right)$ from the $\mathrm{I}_{\mathrm{dgc} \_ \text {ref }}$ produced by the DC voltage regulator and specified $\mathrm{I}_{\mathrm{q}_{\mathrm{r}} \text { ref }}$ reference. The current regulator is assisted by feed forward terms which predict the $\mathrm{C}_{\text {grid }}$ output voltage.

\subsection{Pitch angle control system}

The pitch angle is kept constant at zero degree until the speed reaches point $\mathrm{D}$ speed of the tracking characteristic. Beyond point $\mathrm{D}$ the pitch angle is proportional to the speed deviation from point $\mathrm{D}$ speed. For electromagnetic transients in power systems the pitch angle control is of less interest. The wind speed should be selected such that the rotational speed is less than the speed at point $\mathrm{D}$.

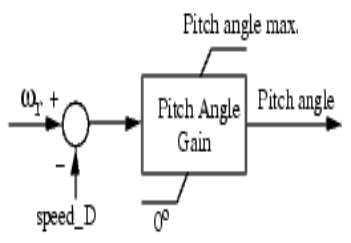

Fig.5 pitch angle control system 


\section{CONTROL STRATEGIES}

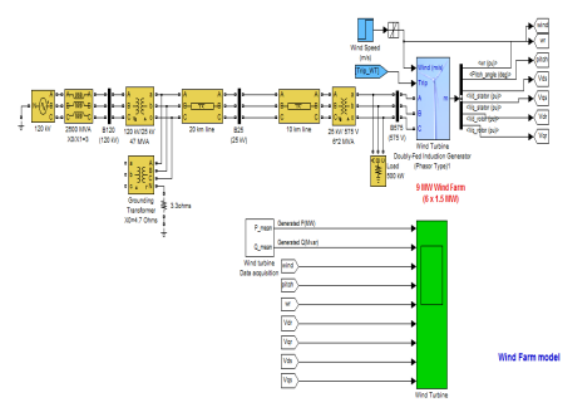

fig.6. $9 \mathrm{mw}$ wind farm using dfig (simulink model)

\subsection{Wind farm DFIG phasor model description}

A 9-MW wind farm consisting of six 1.5 MW wind turbines connected to a 25-kV distribution system exports power to a $120-\mathrm{kV}$ grid through a $30-\mathrm{km}, 25-\mathrm{kV}$ feeder. A $2300 \mathrm{~V}, 2-\mathrm{MVA}$ plant consisting of a motor load (1.68 MW induction motor at $0.93 \mathrm{PF}$ ) and of a $200-\mathrm{kW}$ resistive load is connected on the same feeder at bus B25 as shown in Fig.6.

\subsection{PI controller}

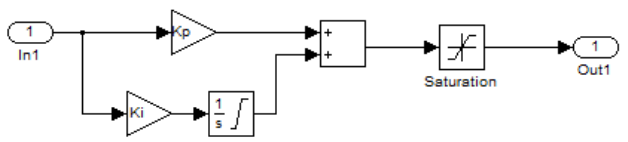

Fig.7. simulink diagram of pi controller.

\subsection{Design of Neural network}

Newlind function is used to dsign a linear layer.

Syntax

net $=$ newlind $(\mathrm{P}, \mathrm{T}, \mathrm{Pi})$

\section{Description}

net $=$ newlind $(\mathrm{P}, \mathrm{T}, \mathrm{Pi})$ takes these input arguments,

$\mathrm{P}$ R-by-Q matrix of $\mathrm{Q}$ input vectors

T S-by-Q matrix of Q target class vectors

Pi 1-by-ID cell array of initial input delay states

where each element $\mathrm{Pi}\{\mathrm{i}, \mathrm{k}\}$ is an Ri-by-Q matrix, and the default $=[]$; and returns a linear layer designed to output $\mathrm{T}$ (with minimum sum square error) given input $\mathrm{P}$.

\section{Algorithms}

newlind calculates weight $\mathrm{W}$ and bias $\mathrm{B}$ values for a linear layer from inputs $\mathrm{P}$ and targets $\mathrm{T}$ by solving this linear equation in the least squares sense:

$[\mathrm{W} \mathrm{b}] *[\mathrm{P} ;$ ones $]=\mathrm{T}$

\subsection{Artificial Neural Network (ANN) Control for Grid side}




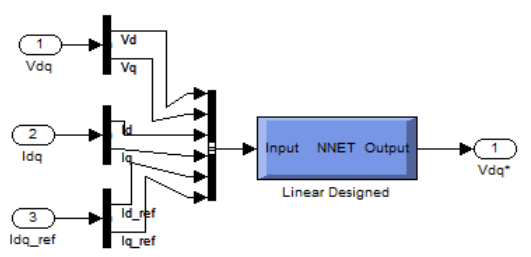

Fig.8 ann controller (simulink model) for grid side control.

Artificial Neural Network (ANN) controller designed consists of six inputs, one hidden layer. Linear function is used at the input and output layer.

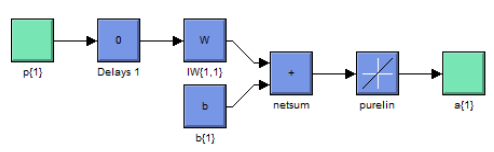

fig.9 ann layer model.

\section{5 . Rotor side NN controller}

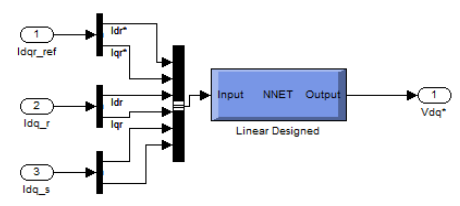

Fig.10 ann controller simulink model for rotor side.

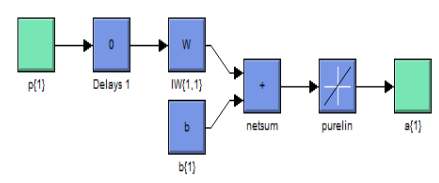

Fig.11 ann layer model.

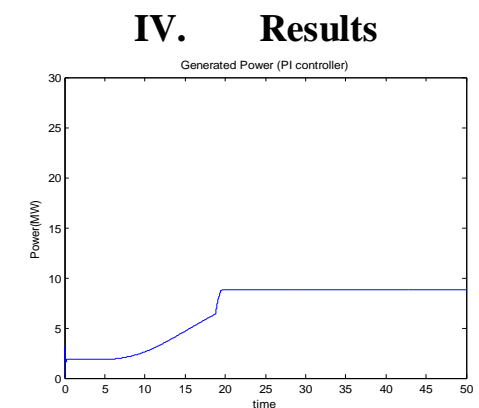

Fig 12. System response with pi controller.

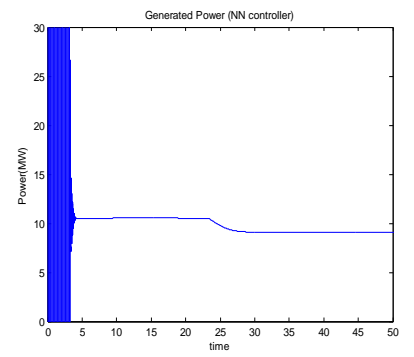

Fig 13. System response with neural network controller. 
The system response with PI controller is shown in Fig.11. The response of the system using PI controller is slow. The system takes some time to achieve optimum value of power. The system response with NN controller is shown in Fig.12. The response of the system using NN controller is fast in order to achieve optimum value of power.

\section{Conclusion}

The neural network controller designed for DFIG has been connected to a variable speed wind Turbine. The system is validated using MATLAB/Simulink simulation. The grid-side and rotor-side converters reference voltages are estimated as the neural network is trained. The comparative study between the two controllers shows that ANN is very effective on the stabilization of the system. Processing becomes simpler as computational complexity is reduced. The major advantage of ANN is that it has no mathematical model so the computational time is reduced.

\section{Appendix}

Table I

DOUBLY FED INDUCTION GENERATOR

\begin{tabular}{|l|l|}
\hline Parameters at rated speed & DFIG \\
\hline Rated power [MW] & 9 \\
\hline Stator Resistance [PU] & 0.000706 \\
\hline Stator Leakage Inductance [PU] & 0.171 \\
\hline Rotor Resistance [PU] & 0.005 \\
\hline Rotor Leakage Inductance [PU] & 0.156 \\
\hline Magnetizing Inductance [PU] & 2.9 \\
\hline Number of pole pairs & 3 \\
\hline Moment of Inertia [H(s)] & 5.04 \\
\hline
\end{tabular}

Table II

WIND TURBINE DATA

\begin{tabular}{|l|l|}
\hline \multicolumn{2}{|c|}{ Parameters } \\
\hline Output power & $9 \mathrm{MW}$ \\
\hline Pitch angle controller gain & 500 \\
\hline Maximum pitch angle & 45 \\
\hline
\end{tabular}

\section{REFERENCES}

[1] Hansen, L.H.,Helle L., Blaabjerg F., Ritchie E., Munk-Nielsen S.,Bindner, H., Sørensen, P. and Bak-Jensen, B., “Conceptual survey of Generators and Power Electronics for Wind Turbines”, Risø National Laboratory, Roskilde, Denmark, Ris $\emptyset-\mathrm{R}-1205$ (EN), 2001.

[2] Hansen A.D., "Wind Power in Power systems", John Wiley\&Sons, Ltd, 24 p, Denmark, 2004.

[3] Florin Iov, "Contributions to Modeling, Analysis \& Simulation of AC Drive Systems application to large wind turbines", Ph.D Thesis, University Dunarea de Jos, Galati, Romania, 2003.

[4] Florin Iov, "Contributions to Modeling, Analysis \& Simulation of AC Drive Systems application to large wind turbines", Ph.D Thesis, University Dunarea de Jos, Galati, Romania, 2003.

[5] P. Vas, "Sensorless vector and direct torque control", Oxford University Press, 1998

[6] Qiao W, Venayagamoorthy GK, Harley RG. Design of optimal PI controllers for doubly fed induction generators driven by wind turbines using particle swarm optimization. In: Proc. International Joint Conference on Neural Networks, Sheraton VancouverWallCentreHotel, Vancouver,BC, Canada. July 2006: p.1982-1987.

[7] Simo es MG, Bose BK, Spiegel RJ. Design and performance evaluation of a fuzzy-logic-based variable-speed wind generation system. IEEE Transactionson Industry Applications 1997;33(4):956-65. 